\title{
DO OBJETIVISMO À CONCEPTUALIZAÇÃO SOCIOCOGNITIVA: HISTÓRICO E PERSPECTIVAS SOBRE O ESTUDO DO SIGNIFICADO
}

\section{FROM OBJECTIVISM TO SOCIOCOGNITIVE CONCEPTUALIZATION: HISTORY AND PERSPECTIVES ON THE STUDY OF MEANING}

\author{
Aline Nardes dos Santos \\ Doutoranda em Linguística Aplicada pela Universidade do Vale do Rio dos Sinos \\ Mestre em Linguística Aplicada pela Universidade do Vale do Rio dos Sinos \\ E-mail: aline.nardes@gmail.com \\ Rove Luiza de Oliveira Chishman \\ Doutora em Linguística Aplicada Pontifícia Universidade Católica do Rio Grande do Sul \\ Professora do Programa de Pós-Graduação em Linguística da Universidade do Vale do Rio dos Sinos \\ E-mail: rove@unisinos.br
}

\section{RESUMO}

Este artigo tem como objetivo refletir sobre a noção de significado em uma perspectiva ampla, abrangendo concepções filosóficas, linguísticas e culturais. Para isso, contrasta-se a visão tradicional ou objetivista do significado com a visão experiencialista, na qual se insere o paradigma da Linguística Cognitiva e sua proposta de estudo do significado como conceptualização. Verifica-se que, conforme o objetivismo, a produção de significado está totalmente dissociada de características sociais, culturais e subjetivas dos falantes. Já o experiencialismo coloca em evidência os processos cognitivos, imaginativos e intersubjetivos que permeiam o significado. Em vista disso, conclui-se que a agenda dos estudos do significado na atualidade, no que se refere a abordagens experiencialistas e sociocognitivas, têm valorizado cada vez mais os processos de significação em seus contextos sociais, culturais e interacionais.

Palavras-chave: Objetivismo. Experiencialismo. Linguística Cognitiva. Sociocognitivismo.

\section{ABSTRACT}

This article aims to reflect on the notion of meaning in a broad perspective, covering philosophical, linguistic and cultural conceptions. For this, it is contrasted the traditional view or objectivist of meaning with experientialist vision, which fits the paradigm of Cognitive Linguistics and its study proposal of meaning study as a conceptualization. It is found that, as objectivism, the production of meaning is totally dissociated from social, cultural and subjective of the speakers. 
Already experientialism highlights the cognitive, imaginative and inter-subjective processes that permeate the meaning. In view of this, it is concluded that the research agenda of meaning in the present, in relation to experientialists and socio-cognitive approaches have valued increasingly the significance of processes in their social, cultural and interactional contexts.

Keywords: Objectivism. Experientialism. Cognitive Linguistics. Social-cognitivism.

\section{INTRODUÇÃO}

Significado: nenhum problema para os falantes; muitos problemas para os linguistas. Parafraseando aqui o professor Augusto Soares da Silva ${ }^{1}$, é inquestionável a naturalidade com que falantes operam mecanismos de produção de sentido - afinal, o ato de apreendermos e produzirmos significado são tão naturais quanto a nossa aptidão para a comunicação e a interação em sociedade. Desse modo, como afirma Borges Neto (1999),

[...] frente a alguns fenômenos mais ou menos óbvios as pessoas dizem coisas com a linguagem e compreendem coisas quando diante de expressões linguísticas; cabe aos teóricos "criar", "construir" um elemento de explicação, e uma das possibilidades é postular a existência de alguma coisa que se denomine "significado". (BORGES NETO, 1999, p. 167-168).

Esse questionamento relativo ao maquinário que subjaz à significação, que se constitui, segundo Lyons (1997, p. 26), na "pergunta mais fundamental a que a semântica linguística e não linguística tenta dar uma resposta cientificamente satisfatória", ${ }^{2}$, motivou muitas investigações linguístico-filosóficas. Ao longo da história, tanto a filosofia quanto a linguística têm desenvolvido teorias sobre o significado que propõem desde a mais pura separação entre racionalidade e percepção humana - o significado como algo independente de nossa experiência até análises ancoradas no uso linguístico, nas interações e no contexto sociocultural dos falantes. Em outras palavras, o primeiro eixo postula que "a linguagem significa"; o segundo, que "os falantes significam com a linguagem”. (BORGES NETO, 1999, p. 168).

A abordagem do significado por meio da Linguística Cognitiva (LC) corresponde ao segundo extremo dessa gradação, visto que leva em conta a experiência dos falantes, assumindo, assim, uma visão experiencialista do significado, paradigma postulado por Lakoff e Johnson (LAKOFF, [1987]1990; JOHNSON, 1987; LAKOFF; JOHNSON, [1980]2003). Essa perspectiva difere-se do primeiro extremo, caracterizado como tendo uma visão objetivista, a qual, ao propor um estudo do significado, dissocia a mente do corpo, a razão da emoção, o conceptual do concreto (JOHNSON, 1987). Considerando essas perspectivas, este artigo tem como objetivo 
contextualizar o estudo do significado no âmbito da Linguística Cognitiva, explorando a noção de conceptualização. Para mais bem situar o empreendimento da LC, uma abordagem que privilegia o significado como processo dinâmico, a primeira seção traz uma visão panorâmica da perspectiva oposta, e até então predominante, a que se pode chamar de "visão tradicional" ou objetivista do significado (LAKOFF, [1987]1990; LAKOFF; JOHNSON, [1980]2003). A partir disso, tratamos dos postulados do experiencialismo, para então contextualizamos os pilares da Linguística Cognitiva e sua proposta de estudo do significado como conceptualização.

\section{2 “A LINGUAGEM SIGNIFICA”: A VISÃO DE SIGNIFICADO NO PARADIGMA OBJETIVISTA}

Na obra clássica Women, Fire and Dangerous Things, George Lakoff ([1987]1990) introduz o objetivismo fazendo as seguintes afirmações: (a) a filosofia importa mais do que se imagina, porque a visão filosófica clássica de mundo afetou a nossa forma de pensar e enxergar a realidade; (b) o paradigma filosófico do objetivismo moldou, por muito tempo, a linguística como disciplina e, por consequência, moldou também a abordagem do significado nesse contexto.

Essas considerações reforçam a importância de, antes de tratarmos da nossa visão de significado, que é pautada no experiencialismo, trazermos uma perspectiva panorâmica do objetivismo e de suas bases filosóficas. Naturalmente, é necessário levarmos em conta que, embora sejam áreas relacionadas, filosofia e linguística têm motivações diferentes em relação ao estudo do significado. Conforme explica Coulson (1997),

Filósofos e linguistas têm se impressionado por coisas diferentes quanto à competência de linguagem humana, e a semântica tem sido moldada por ambos os tipos de interesse. Para filósofos, o interessante da linguagem é sua intencionalidade ou tematicidade. Como um conjunto arbitrário de símbolos pode representar coisas no mundo? [...] O problema do filósofo de como "gato" pode representar um gato ${ }^{3}$ levou a uma ênfase na verdade e na referência (COULSON, 1997, p. 3, grifo da autora). ${ }^{4}$

A autora toca em dois pontos fundamentais para compreendermos como a abordagem do significado se deu a partir da filosofia: a preocupação com a referência às coisas no mundo e o foco nas condições de verdade ${ }^{5}$ que estabeleceriam uma expressão como verdadeira ou falsa.

A primeira abordagem filosófica relativa à referência de entidades do mundo foi a teoria da referência direta (MARTIN, 2006). Como o nome já indica, os exemplos que reforçariam a plausibilidade da teoria seriam os nomes próprios. No entanto, essa teoria encontra obstáculos mesmo quando se pensa em nomes próprios, dado que o referente nem sempre concerne ao mundo real. Por exemplo, as personagens Garfield e Félix, de desenhos animados, não estão no mundo real; assim, conforme a teoria da referência direta, esses nomes não teriam significado algum. 
Existem casos ainda mais problemáticos, envolvendo o tratamento do significado sob perspectivas diferentes em relação à mesma entidade, sem que isso tenha a ver com características inerentes ao referente: os gregos, ao avistarem Vênus pela manhã, chamavam-no de Eósforo ("estrela da manhã"); porém, a mesma entidade vista no fim da tarde era referenciada como Héspero ("estrela da tarde"). Em situações como essa, a teoria da referência direta não daria conta de descrever o significado.

De modo a propor uma solução para esse problema relativo a referências não binárias, surge a abordagem do sentido e da referência proposta por Frege. Para o filósofo, o referente seria a entidade designada por uma expressão linguística; já o sentido corresponderia a uma forma de apresentação desse referente, ou a um modo específico de pensar sobre essa entidade (MARTIN, 2006). Dessa forma, se, para os gregos, Vênus era, ao mesmo tempo, Eósforo e Héspero, não haveria discrepância porque, dada a distinção entre sentido e referência, poder-se-ia considerar a existência de dois sentidos para um mesmo referente. Esse quadro referencial muda se pensarmos na contemporaneidade, em que a ciência há muito revelou serem Eósforo, Héspero e Vênus sentidos relativos ao mesmo referente.

A visão do significado pautada em condições de verdade, que engloba a proposta fregeana, tem o filósofo Tarski como um de seus principais formuladores (BORGES NETO, 1999). Martin (2006) explica esse paradigma por meio de sua relação com a aritmética consideremos, por exemplo, a seguinte função: $y \times \mathbf{2}=\mathbf{8}$.

Caso o argumento de Y seja 4, o valor é VERDADEIRO; caso seja outro número, o valor é FALSO. Assumindo a formulação tarskiana, diríamos que o argumento de $\mathbf{y}$ é verdadeiro se, $e$ somente se, o valor é 4. Transpondo esse pressuposto à linguagem, na sentença Lila é uma gata cinza, desde que tivéssemos ciência daquilo que implica a gata Lila ser cinza, saberíamos o significado da sentença e reconheceríamos que é verdadeira - o mesmo processo justifica o conhecido exemplo do gato sobre o tapete. Esse pressuposto moldou não apenas a lógica na filosofia, mas também a semântica formal na linguística (KAUFFMANN, 2010).

Abordagens como essas são categorizadas como sendo objetivistas, em contraposição ao empreendimento experiencialista de que trataremos na próxima seção. Como podemos perceber, essas teorias

[...] assumem que o pensamento racional consiste na manipulação de símbolos abstratos e que esses símbolos adquirem seu significado por meio de uma correspondência com o mundo, objetivamente construído, isto é, independente do entendimento de qualquer organismo. [...] Na visão objetivista, todo o pensamento racional envolve a manipulação de símbolos abstratos aos quais é dado significado apenas por meio de correspondências convencionais com coisas no mundo externo. (LAKOFF, [1987]1990, p. 12, grifo do autor). ${ }^{6}$ 
É importante ressaltar que não estamos tratando do objetivismo como empreendimento homogêneo, mas sim como um conjunto de abordagens que partilham certas características. No que concerne ao estudo da linguagem, dentre as principais correntes que fomentaram essa posição epistemológica, estão o positivismo lógico e a tradição fregeana na filosofia e, na linguística, o neorracionalismo chomskyano ${ }^{7}$ (LAKOFF; JOHNSON, [1980]2003).

O termo objetivismo já indica que, nesse paradigma, a realidade é vista em termos objetivos, dissociada dos seres que a constituem. Trata-se da visão do Olho de Deus (JOHNSON, 1987), ou seja, a defesa de que existe uma perspectiva correta sobre o mundo como ele realmente é. Dessa forma, desconsiderando-se quaisquer influências subjetivas, a realidade teria uma estrutura totalmente racional, sendo a linguagem utilizada para designar entidades nesse mundo objetivo. A verdade, nesse sentido, é "[...] uma questão de adaptação das palavras ao mundo" (LAKOFF; JOHNSON, [1980]2003, p. 197) ${ }^{8}$, independentemente de como os falantes usam a linguagem. A mente, nesse contexto, pode ser comparada a um computador que efetua operações algorítmicas, consistindo em um "espelho da natureza" (LAKOFF, [1987]1990, p. 12, grifo do autor $^{9}$ ), visto que apenas reflete, isomorficamente, a realidade objetiva e toda a sua estrutura lógica.

Considerando essa dissociação entre o mundo e os falantes no processo de produção de significado, em que consistiria a comunicação humana? Lakoff e Johnson ([1980]2003) utilizam a metáfora do conduto para ilustrar essa perspectiva. Segundo essa metáfora, as expressões linguísticas são contêineres, ou seja, carregam significados que já estão prontos no mundo. Dessa forma, os fins comunicativos da linguagem são vistos como uma mera questão de transmissão de “[...] uma mensagem com um significado fixo a um ouvinte." (LAKOFF; JOHNSON, [1980]2003, p. 197$)^{10}$.

Compreender premissas objetivistas em relação à linguagem e ao significado é de suma importância para que percebamos como esse paradigma criou mitos até hoje presentes em visões epistemológicas e, como reforça Johnson (1987), em nossas vidas, consolidando preceitos que se tornaram parte do senso comum em nossa cultura. A proposta que contesta esse modelo e que embasa os pilares da Linguística Cognitiva no século XX tem como principais protagonistas Lakoff e Johnson, considerados, como ressalta Langacker (1997), os pais do realismo experiencial na Linguística Cognitiva e na Filosofia.

\section{3 “OS FALANTES SIGNIFICAM COM A LINGUAGEM”: REALISMO EXPERIENCIAL}

O objetivismo passa a ser questionado a partir do momento em que a teoria de Darwin ganha força ${ }^{11}$, mostrando que as habilidades humanas são evoluções das habilidades características de outros animais. Tal contestação é novamente reforçada a partir dos anos 1970, 
por meio do estabelecimento da ciência cognitiva - disciplina que tem como objeto de estudo sistemas conceptuais (LAKOFF; JOHNSON, 1999). As descobertas realizadas nesse âmbito abrem precedentes para se considerar que o ser humano, não apresentando um funcionamento diferente daquele que caracteriza outras espécies, possui um modo cognitivo de funcionamento tão ligado às suas experiências corpóreas, perceptuais e motoras quanto os outros animais. Essa premissa é um dos principais pilares do realismo experiencial, ou experiencialismo, o qual postula que,

[...] como animais, temos corpos conectados ao mundo natural, de tal modo que nossa consciência e racionalidade estão ligadas às nossas orientações corpóreas e interações no e com nosso ambiente. Nossa corporificação é essencial para aquilo que somos, para aquilo que o significado é, e para nossa habilidade de esboçar inferências racionais e ser criativos. (JOHNSON, 1987, p. 38). ${ }^{12}$

Desse modo, o cerne do contraste com o pensamento objetivista reside no fato de que o experiencialismo vê a racionalidade humana - e, consequentemente, o modo como se dá a formação de conceitos - como um aspecto pautado na natureza e na experiência dos organismos que protagonizam esses processos de cognição e significação. Nesse contexto, a experiência é considerada em sentido bastante amplo, não abrangendo apenas as características físicas do ser humano: "Inclui [...] não meramente percepção, movimento etc., mas especialmente a constituição interna geneticamente adquirida do organismo e a natureza de suas interações, tanto no seu ambiente físico quanto no seu ambiente social”. (LAKOFF, [1987]1990, p. 15) ${ }^{13}$.

Nessa visão epistemológica, significar implica significar para os falantes, dado que não se tem uma visão do mundo como algo objetivamente construído. Mesmo se retomarmos o clássico e comportado exemplo do gato que está sobre um tapete, podemos perceber que há, nessa constatação, uma perspectiva que revela muito sobre a experiência de um ser humano que enxerga a realidade a partir de sua constituição corpórea: se um falante vê um gato sobre um tapete, é porque percebe o mundo por meio de sua posição ereta - os pés no chão em uma extremidade; a cabeça em outro extremo - em um local onde a força gravitacional está presente. Como reforça Turner (1991 apud JOHNSON, 2005), se vivêssemos em um meio líquido, na ausência de um eixo vertical para cima/para baixo, dentre outras noções espaciais, nossa experiência corpórea não teria o mesmo significado - da mesma forma, se ocupássemos um espaço totalmente sem gravidade, nem gato nem tapete ocupariam posições tão óbvias. Esses fatores apontam para o fato de nosso pensamento ser inerentemente corporificado. Como explicam Lakoff e Johnson (1999, p. 4),

A razão não é descorporificada, conforme a tradição tem amplamente sustentado, mas resulta da natureza de nossos cérebros, corpos, e experiência corporal. [...] Os mesmos mecanismos neurais e cognitivos que nos permitem perceber e nos mover também criam nossos sistemas conceptuais e modos de raciocinar. [...] Em suma, a razão não é, de nenhuma forma, um traço transcendental do universo ou da mente descorporificada. Em vez disso, é moldada crucialmente pelas peculiaridades de nossos corpos humanos, pelos detalhes extraordinários da estrutura neural de nossos cérebros, e pelas especificidades de nosso funcionamento diário no mundo. ${ }^{14}$ 
Conforme vimos na seção anterior, o objetivismo estabelece que as palavras e as respectivas representações mentais são relacionadas por meio de uma única maneira: a correspondência com entidades concretas no mundo. No entanto, a visão experiencialista coloca essa postulação em xeque ao mostrar que processos de significado não se dão meramente por meio da referência a entidades no mundo, nem estão condicionados às condições de verdade. Por exemplo, se um falante, ao partir do exemplo clássico do felino, afirmar eu sou o gato e os meus inimigos são o tapete, não se trata de uma referência direta ao gato ou ao tapete; é um processo mais complexo, que envolve a projeção da posição do gato em relação ao tapete para uma situação de superioridade do falante no que concerne aos seus inimigos. Projeções como essa evidenciam o papel primordial que a imaginação humana possui em processos de significado, desempenhando “[...] um papel central na constituição da racionalidade.” (JOHNSON, 1987, p. 9) ${ }^{15}$.

Em relação ao fato de o objetivismo descartar quaisquer influências não objetivas em processos de significação, outro exemplo de projeção pode servir para mostrar como uma perspectiva que não considere questões intersubjetivas torna-se bastante limitada: suponhamos que um chocólatra, segurando uma barra de chocolate, faça a seguinte afirmação: eu sou um gato e este é o meu Whiskas Sachê. Para se compreender essa sentença, é necessário não apenas considerar a projeção gato/humano e chocolate/Whiskas Sachê, mas também levar em conta uma apreciação positiva de um tipo de alimento para gatos. É por isso que Tomasello (2003) defende uma visão de símbolos linguísticos como construtos intersubjetivos, dado que é necessário que usuários partilhem de certas informações para compreenderem projeções como essa. Assim como no exemplo anterior, tal aspecto também mostra como os usos linguísticos vão muito além da referência objetiva a seres concretos no mundo.

Essas questões evidenciam que conceitos humanos, sob a ótica experiencialista, somente podem ser compreendidos se for levada em conta a natureza da experiência humana, que está ancorada em certos parâmetros culturais (JOHNSON, 1987). Como reforça Langacker (1997, p. 233), uma das facetas mais importantes relativas ao contexto em que interagimos e nos desenvolvemos “[...] consiste na interação com outras pessoas e outras mentes. Isso leva ao reconhecimento mútuo [...] bem como à convergência substancial nos mundos mentais construídos.” (LANGACKER, 1997, p. 233). 16 Não há, portanto, uma relação direta entre significado e realidade objetiva, da forma como postulam objetivistas, visto que, conforme defende o experiencialismo, existem processos imaginativos que perpassam os caminhos para a significação na linguagem humana. Ou seja, “O significado não é uma coisa; ele envolve aquilo 
que é significativo para nós. Nada é significativo em si. Significação deriva da experiência de funcionar como um ser de certo tipo em um ambiente de certo tipo." (LAKOFF, [1987]1990, p. 292) 17.

Também é importante levar em consideração que, nessa proposta de visão experiencialista de Lakoff e Johnson, assim como aspectos do objetivismo são preservados, o mesmo se pode dizer quanto ao subjetivismo, ou seja, quanto à ideia de que, conforme referem os autores, a produção de significado funcionaria tal qual explica a personagem Humpty Dumpty, em Alice Através do Espelho: "Quando eu uso uma palavra [...], ela significa exatamente aquilo que eu quero que signifique: nem mais nem menos." (CARROL, [1865]2010, p. 265). Apesar de rejeitar esse postulado de que o conhecimento humano estaria totalmente condicionado à subjetividade e dissociado de circunstâncias externas à racionalidade humana, os autores consideram a importância de se levar em conta os fatores subjetivos que permeiam significado - a linguagem significa sempre para alguém (LAKOFF; JOHNSON, [1980]2003).

O realismo experiencial é um dos principais pilares que sustentam a noção de significado como conceptualização, aspecto de que trataremos na seção a seguir.

\subsection{CONCEPTUALIZAÇÃO: O SIGNIFICADO COMO PROCESSO DINÂMICO}

Abordados os paradigmas objetivista e experiencialista no contexto do estudo do significado, nosso percurso reflexivo passa a focar nos seguintes aspectos: (a) a pertinência de uma abordagem linguístico-cognitiva para o estudo do significado; e (b) a concepção de significado como processo de conceptualização. Para isso, apresentamos, a seguir, a Linguística Cognitiva enquanto empreendimento pautado no realismo experiencial, para então discutirmos seus pressupostos relativos ao estudo do significado.

\subsubsection{A primazia do significado na Linguística Cognitiva}

Conforme indicamos ao longo do artigo, a Linguística Cognitiva surge a partir do paradigma experiencialista, que, por sua vez, é estabelecido no âmbito da ciência cognitiva. Desse modo, os postulados linguístico-cognitivos contrastam-se com as premissas objetivistas no que tange a cognição e significado. Retomando nossa seção sobre objetivismo, quanto à cognição, se a mente humana simplesmente reflete uma realidade objetiva, os processos cognitivos subjacentes consistem em meras operações mecânicas que viabilizam a correspondência palavra-mundo. Em 
termos de significado, portanto, não haveria que se considerar influências subjetivas, externas a essa correspondência, de modo que uma semântica objetivista implica considerar se determinadas expressões linguísticas são verdadeiras ou falsas no que concerne à correspondência com o mundo objetivo (LAKOFF, [1987] 1990). A partir da perspectiva experiencialista, a Linguística Cognitiva evidencia como esses postulados são consideravelmente limitados no que se refere ao estudo de processos de significação, visto que "[...] eliminam a organização cognitiva do sistema linguístico". (SWEETSER, 1990, p. 4). ${ }^{18}$

A Linguística Cognitiva não consiste em uma teoria homogênea, mas sim num empreendimento que agrupa diversas abordagens que se sobrepõem parcialmente (GEERAERTS, 2006) e que partilham de pressupostos relativos à concepção de linguagem e de cognição. Dentre os protagonistas desse movimento, iniciado ao final dos anos 1970, destacam-se Lakoff ([1987]1990), Langacker (1987) e Talmy (1987). A LC pode ser considerada uma teoria pautada na compreensão e no uso linguístico, cujo objetivo é mostrar como a linguagem está ancorada na cognição humana. Nessa perspectiva, o único objetivo legítimo e científico no estudo da linguagem é o estudo do significado, bem como do papel dos processos cognitivos nesse fenômeno. (KÖVECSES, 2006).

Como explica Taylor (2005), a LC se insere no panorama da ciência cognitiva por preocupar-se em explicar como a linguagem reflete conteúdo conceptual, tratando dos significados na condição de entidades mentais. Esse propósito ancora-se no chamado compromisso cognitivo da área, representando seu comprometimento em "[...] fornecer uma caracterização dos princípios gerais para a linguagem que estão em consonância com aquilo que se sabe sobre a mente e o cérebro a partir de outras disciplinas" (EVANS; BERGEN; ZINKEN, 2007, p. 4) $)^{19}$. A Linguística Cognitiva constitui-se, portanto, em um campo multidisciplinar que prima pelo diálogo com outras áreas, como a psicologia, a neurociência e a ciência da computação, baseando-se nas descobertas que comprovam empiricamente a forma como a cognição funciona.

Conforme Salomão (2006), apesar de todas as teorias da LC configurarem um panorama bastante heterogêneo, pode-se traçar um fio condutor que une esses aportes teóricos por meio de certos postulados - dentre eles, ver a linguagem como uma habilidade dependente dos demais processos cognitivos, a qual, portanto, não pode ser vista como um módulo isolado do restante do cérebro. Dessa forma, as teorias filiadas à Linguística Cognitiva propõem uma abordagem mais abrangente da linguagem, levando-se em consideração as inter-relações entre cognição, significado e experiência. Assim sendo, considera-se que o significado é baseado no uso e na experiência dos falantes, refutando-se tendências de abordagens anteriores em abstrair a 
linguagem de seu uso e considerar fenômenos semânticos e pragmáticos como periféricos aos estudos linguísticos. Nas palavras de Fauconnier, (2003, p. 2$)^{20}$ “A linguagem não 'representa' o significado; ela remete à construção do significado em contextos particulares contendo modelos culturais particulares e recursos cognitivos." Defende-se, assim, que os usos linguísticos são profundamente motivados.

Esses pressupostos evidenciam, portanto, que o significado de uma expressão envolve a recuperação de informação extralinguística - por exemplo, ao conceptualizar a unidade café (sentido de bebida), o falante não recupera apenas a informação linguística de que é uma bebida feita com grãos do cafeeiro: todo o seu conhecimento de mundo e sua experiência relativos à bebida serão ativados, podendo incluir o gosto do café, os efeitos da cafeína, os momentos do dia em que o consome, dentre outras informações. Desse modo, por meio dessa perspectiva, compreendemos que “[...] um significado lexical reside em um modo particular de acessar conhecimentos ilimitados pertencentes a certo tipo de entidade." (LANGACKER, 2008, p. 40, grifo do autor $)^{21}$. Esse pressuposto remete à noção de conhecimento enciclopédico, um dos principais pilares que sustentam as teorias da LC.

Segundo Langacker (1999), a noção de conhecimento enciclopédico é embasada não apenas no realismo experiencial, mas também na semântica enciclopédica proposta por Haiman (1980). Em seu artigo intitulado Dictionaries and Encyclopedias, o autor questiona a posição de lexicógrafos que até então vinham elaborando definições a partir da distinção saussuriana significante-significado, considerando esse significado de dicionário como algo independente de aspectos experienciais. Da mesma forma, Haiman refuta o argumento de filósofos e linguistas quanto à possibilidade de separação entre "palavras-dicionário", correspondendo a significados supostamente mais fenomenológicos e cotidianos que deveriam ser encontrados em dicionários, e "palavras-objeto", relativas a fatos concretos que, desse modo, comporiam enciclopédias ${ }^{22}$. Para ele, não haveria essa distinção entre dicionários e enciclopédias que tantos teóricos buscavam estabelecer, visto que conhecimento semântico está atrelado a conhecimento cultural, de modo que, "Sem experiência, não há pensamento, e certamente não há linguagem.” (HAIMAN, 1980, p. $337)^{23}$.

A figura a seguir representa essa distinção entre visão dicionarística do significado (dentre todos os conhecimentos relativos a uma expressão, apenas o linguístico é considerado) e visão enciclopédica, ilustrando diversas outras informações que podem ser ativadas no processo de significação, de forma mais central ou mais periférica: 


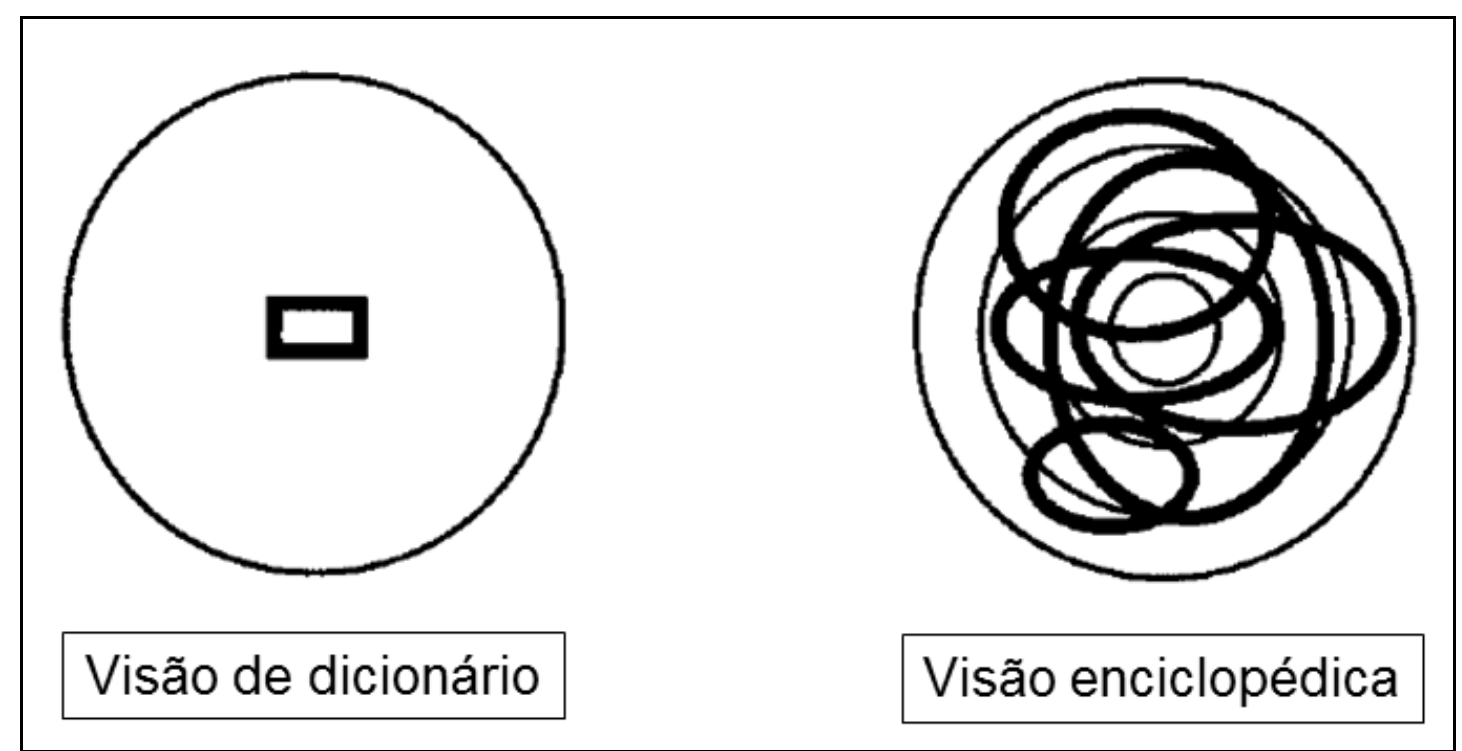

Figura 1: visão de dicionário $X$ visão enciclopédica

Fonte: adaptado de Langacker (2008, p. 39).

Dentre os principais fenômenos estudados pela Linguística Cognitiva, destacamos o processo de categorização - ou seja, a habilidade humana de agrupar diferentes entidades como sendo instâncias da mesma espécie (TAYLOR, 2009) -, que é compreendido por meio da noção de protótipo, conceito fundamental para compreendermos os princípios basilares dessas teorias.

Fundamentada nas descobertas de pesquisadores como Rosch (1973) - expoente da psicologia cognitiva que marcou consideravelmente o campo com suas investigações sobre categorização -, a Linguística Cognitiva defende que a categorização não deve ser entendida através de um processo binário de pertencimento ou não pertencimento a determinada categoria, como postula a visão aristotélica, mas sim a partir da noção de prototipicidade ou de efeito prototípico. Conforme a autora, todos os objetos que pertencem a certas categorias têm o mesmo status; no entanto, alguns exemplos são considerados mais prototípicos que outros. Como explica didaticamente Geeraerts (2006, p. 1), entender o conceito de pássaro vai muito além de identificar os membros dessa categoria a partir de condições necessárias e suficientes:

[...] você pode definir os pássaros como certo tipo de animal com certas características (como ter asas, ser capaz de voar, nascer de ovos), mas se quiser ter uma boa noção cognitiva do que são os pássaros, terá de checar alguns pássaros típicos, como sabiás, pardais e pombas, e talvez também alguns menos típicos, como galinhas e avestruzes. ${ }^{24}$

Desse modo, para entenderem o significado de uma palavra, os falantes recorrem a um acervo mental de protótipos. Para a LC, a habilidade de categorização não só se reflete na organização linguística, como também explica o modo de funcionamento da cognição humana. Essa noção de efeito prototípico resulta em uma abordagem-modelo para estudos de fenômenos 
linguísticos e conceptuais sob o escopo da Linguística Cognitiva, incluindo-se as abordagens mais voltadas à gramática: a LC, como explica Lakoff ([1987]1990), defende que todas as categorias linguísticas refletem, em alguma medida, a noção de protótipo, tendo cada uma delas os seus elementos e características mais centrais e mais periféricos.

A perspectiva linguístico-cognitiva de significado, portanto, reside em uma ideia integrada de cognição: não sendo a linguagem um módulo isolado de nosso aparato cognitivo, considera-se que nossas habilidades linguísticas funcionam à maneira de outras operações mentais. Dessa forma, se o cérebro consiste em uma vasta rede de relações entre neurônios, conectando todas as atividades cognitivas (TAYLOR, 2002), a linguagem também é uma trama de interconexões com esses vários subsistemas. Além disso, defende-se que esse "[...] nosso órgão principal de fazer significado, a mente/o cérebro, é moldado tanto pela experiência corpórea quanto pela experiência social/cultural." (KÖVECSES, 2006, p. 328). É a partir desses pressupostos que se estabelece uma visão de significado como processo dinâmico ancorado culturalmente, ou seja, como conceptualização.

3.1.2 Eu conceptualizo, tu conceptualizas: a capacidade de conceptualização como locus do significado

Conforme vimos na seção anterior, a Linguística Cognitiva parte do pressuposto de que o estudo da linguagem está ancorado na cognição humana e em seus modos de funcionamento. A partir disso, postula-se uma semântica cognitiva, estabelecendo que o significado esteja primariamente condicionado à nossa experiência cognitiva, que nos permite perceber e construir a realidade por meio da linguagem. Como aponta Coulson (1997, p. 17), o papel dos semanticistas vinculados à LC é tratar do significado como fenômeno cognitivo, levando em conta as:

\footnotetext{
[...] operações cognitivas que realizam a produção e a compreensão de enunciados linguísticos. Visto que a relação entre palavras e o mundo é mediada por atividade cognitiva, o estudo do significado é o estudo de como as palavras são usadas para evocar representações mentais. ${ }^{25}$
}

Complementando essa afirmação com a explicação de Taylor (2005), semanticistas cognitivos levam a sério o postulado de que os significados "estão na mente" e que podem ser identificados como conceptualizações evocadas por expressões linguísticas. Dessa forma, como assinalam Nuyts e Pederson (1997), o comportamento linguístico dos seres humanos consiste em uma fonte valiosa de dados relativos ao modo como conceptualizamos o mundo, visto que explicita e transmite informações conceptuais. É por isso que se parte do pressuposto de que a conceptualização é “o locus do significado” (LANGACKER, 1997, p. 229) ${ }^{26}$. 
Considerando essa perspectiva cognitiva da semântica, tratar de conceptualizações consiste em abordar o significado como processo dinâmico, o qual abrange "[...] novas concepções, bem como conceitos fixos; experiência sensória, sinestésica e emotiva; reconhecimento do contexto imediato (social, físico e linguístico), dentre outros aspectos.” (LANGACKER, 2006, p. 30) ${ }^{27}$. Assim, a conceptualização reside em processos cognitivos que permitem ao falante reconhecer o sentido de determinada palavra ou expressão. Sua dinamicidade está diretamente ligada a essa dimensão de significado como processo realizado cognitivamente em termos neurológicos, o ato de conceptualizar implica um tempo de processamento; além disso, conceptualizações podem constituir em experiências sutilmente diferentes dependendo das escolhas linguísticas feitas pelos falantes.

Entretanto, importa ressaltar que não se está negando que o significado, ancorado na cognição, esteja também condicionado a processos de construção que surgem em contextos interacionais. Langacker (2013) deixa claro que partir de processos cognitivos de conceptualização não implica assumir a posição radical de que "tudo é cognição", visto que, "Na fala, conceptualizamos não apenas aquilo sobre o qual falamos, mas também o contexto e suas dimensões, incluindo nossa avaliação do conhecimento do interlocutor e as suas intenções." $\left(\right.$ LANGACKER, 2013, p. 29) ${ }^{28}$. Ao mesmo tempo, a semântica cognitiva obviamente não é compatível com abordagens interacionistas que defendem que "nada é cognição", como se todos os processos de atribuição de significado surgissem do contexto interativo. O autor é categórico ao afirmar que esse tipo de abordagem não se sustenta, visto que "[...] cabeças vazias não podem falar, interagir ou negociar significado." (LANGACKER, 2013, p. 29) ${ }^{29}$. A partir dessa passagem, compreendemos que tratar de significado como conceptualização é focar no seu ponto de partida, sem desconsiderar que esse processo cognitivo está totalmente atrelado ao funcionamento corpóreo, que, por sua vez, é parte de uma realidade que tem características físicas, sociais e culturais. Desse modo, a semântica cognitiva parte do pressuposto de que "Significados linguísticos também estão ancorados na interação social, sendo negociados por interlocutores com base na avaliação mútua de seu conhecimento, de seus pensamentos e intenções." $(\text { LANGACKER, 2008, p. 4) })^{30}$.

Para compreendermos essa dimensão processual da conceptualização e a importância de se levar em conta o modo como simulamos mentalmente a realidade, é válido mencionarmos o estudo de Matlock (2004), referido por Lakoff (2013) como um exemplo de verificação experimental relativa ao modo como a mente funciona ao processar verbos de movimento 
fictício31: a pesquisadora realizou experimentos com voluntários que foram orientados a ler, o mais rápido possível, pequenas narrativas em uma tela de computador, imaginando os cenários descritos. Após terminar, os participantes respondiam a questionários relativos às histórias, identificando frases que estavam relacionadas às narrativas; o tempo que levavam para responder cada frase era registrado. Os resultados evidenciaram que uma frase como A estrada passa pelo bosque é processada mais rapidamente que A estrada serpenteia pelo bosque, visto que "[...] as pessoas simulam movimento [...] quando tentam entender frases com verbos de movimento fictício." (MATLOCK, 2004, p. 1396) ${ }^{32}$.

Evidências como essa reforçam a escolha de semanticistas cognitivos pelo termo conceptualização, em vez de conceito. Para Langacker (1997), esse uso se opõe propositalmente a conceito porque, em muitas abordagens, este último é caracterizado como entidade dissociada de fatores corpóreos, sociais e culturais e que, portanto, é bastante restrito. Dessa forma, tal aspecto reforça o fato de que, para a semântica cognitiva, "Não há sentidos dados, estáticos, distintos; mas construídos, dinâmicos, flexíveis e negociáveis" (SILVA, 2015) ${ }^{33}$. Segundo o mesmo autor (SILVA, 2009), essa faceta sociocultural do significado tem sido cada vez mais salientada em trabalhos de semântica cognitiva, reforçando que o movimento não é apenas pautado na corporificação, mas também na situacionalidade sociocultural 34 , que enfatiza a natureza interacional e socialmente situada da cognição. Nessa direção, linguistas cognitivos ponderam que o próprio nome Linguística Cognitiva talvez não seja o mais adequado para subsumir esses estudos, e que seria mais pertinente passar-se a utilizar termos como Ciência Social Cognitiva (TURNER, 2001) ou Semântica Cultural (KÖVECSES, 2009), que fazem jus ao escopo atual do empreendimento.

No cenário brasileiro, destacamos o desenvolvimento da Hipótese Sociocognitiva da Linguagem (SALOMÃO, 1997; MIRANDA, 2001), a qual evidencia a relevância de aspectos intersubjetivos para a construção do significado: “A hipótese que [...] adotamos advoga ser a significação uma construção mental produzida pelos sujeitos cognitivos no curso de sua interação comunicativa." (SALOMÃO, 1997, p. 26, grifo da autora). Esse postulado tem como base trabalhos de linguistas como Tomasello (1999), que enfatiza o caráter cultural da comunicação humana. Como explica Miranda (2001), o programa coloca, como cerne de sua agenda investigativa, o caráter social da cognição, deixando em segundo plano os processos cognitivos individuais - postura que, apesar de ser anunciada pela primeira geração de linguistas cognitivos, acaba não sendo concretizada. 


\section{CONSIDERAÇÕES FINAIS}

Neste artigo, iniciamos nossa reflexão explorando a perspectiva da visão objetivista - por vezes chamada de tradicional - do significado, mostrando como a tradição filosófica que consolidou essas bases epistemológicas, e que até hoje tem forte influência sobre o modo como vemos o mundo, moldou uma concepção de significado a partir existência de uma realidade objetiva, na qual a mente humana e suas operações teriam meramente o papel de efetuar correspondências entre linguagem e mundo objetivo. Conforme essa visão, a produção de significado está totalmente dissociada de características sociais, culturais e subjetivas dos falantes - a linguagem, per se, significa.

Na segunda parte, introduzimos o realismo experiencial, ou experiencialismo, postulado por Lakoff ([1987]1990) e Lakoff e Johnson ([1980]2003). Como explicam os autores, a forma como vemos o mundo está diretamente ligada à nossa constituição corpórea, a qual está condicionada a determinados padrões culturais. A partir dessa visão, compreendemos que o significado não está dissociado de características corporais e culturais que nos identificam como seres humanos situados em determinada comunidade. Dessa forma, o realismo experiencial é uma abordagem que coloca em evidência os processos cognitivos, imaginativos e intersubjetivos que permeiam o significado - os falantes é que significam por meio da linguagem.

A última seção foi dedicada ao processo de conceptualização. Para isso, iniciamos a seção abordando os principais pilares do empreendimento da Linguística Cognitiva, bem como o lugar privilegiado dos estudos do significado nesse contexto teórico. Em seguida, tratamos da conceptualização como locus do significado, tal qual definido por Langacker (1997). A partir da semântica cognitiva postulada por linguistas cognitivos, compreendemos que o significado está diretamente relacionado às nossas experiências cognitivas, as quais estão, inegavelmente, atreladas a contextos socioculturais. Desse modo, podemos perceber que as agendas de pesquisa experiencialistas e sociocognitivas têm valorizado cada vez mais os processos de significação em seus contextos sociais, culturais e interacionais.

\section{NOTAS}

1 "Polissemia: nenhum problema para os falantes; muitos problemas para os linguistas." Informação verbal coletada durante a comunicação do professor Augusto Soares da Silva na mesa redonda Polissemia, Cognição e discurso, que ocorreu no I Congresso Ibero-Americano de Semântica Cognitiva (CISCOG), realizado em Salvador, no dia 27 de outubro de 2015.

2 No original: “[...] la pregunta más fundamental a la que la semântica lingüística y no lingüística intenta dar una respuesta científicamente satisfactoria." (LYONS, 1997, p. 26). 
3 Esse trecho remete ao conhecido exemplo o gato está sobre o tapete, bastante recorrente na literatura no inglês: The cat is on the mat (LAKOFF, [1987]1990; LAKOFF; JOHNSON, 1999; COULSON, 1997; 2001).

4 No original: "Philosophers and linguists have each been impressed by different things about human language competence, and semantics has been shaped by both sorts of interests. For philosophers, the interesting thing about language is its intentionality or aboutness. How is that an arbitrary set of symbols can represent things in the world? [...] The philosopher's problem of how "cat" can represent a cat has led to an emphasis on truth and reference." (COULSON, 1997, p. 3, grifo da autora).

5 Dado que tencionamos contextualizar o objetivismo como um todo, neste artigo, estamos nos atendo às abordagens filosóficas ligadas a referência e a condições de verdade. No entanto, é de se considerar que as teorias sobre o significado na filosofia vão muito além desses dois grandes eixos. Por exemplo, Martin (2006) menciona outras abordagens importantes, como a teoria da ideia, de Locke; o significado como uso, defendido principalmente por Wittgenstein e Austin; e o ceticismo de Quine.

6 No original: "[...] assume that rational thought consists of the manipulation of abstract symbols and that these symbols get their meaning via a correspondence with the world, objectively construed, that is, independent of the understanding of any organism. [...] On the objectivist view, all rational thought involves the manipulation of abstract symbols which are given meaning only via conventional correspondences with things in the external world." (LAKOFF, [1987]1990, p. xii, grifo do autor).

7 Os autores ainda explicam que, na linguística, podem-se considerar duas correntes principais: a do objetivismo empírico, liderada por Bloomfield, e a do objetivismo racionalista, que tem como principais expoentes Jackendoff, Sapir, Whorf e Chomsky (LAKOFF; JOHNSON, [1980]2003).

8 No original: “[...] a matter of fitting words into the world." (LAKOFF; JOHNSON, [1980]2003, p. 197).

9 No original: "a mirror of nature.” (LAKOFF, [1987]1990, p. xii, grifo do autor).

${ }^{10}$ No original: “[...] a message with a fixed meaning to a hearer.” (LAKOFF; JOHNSON, [1980]2003, p. 197).

${ }^{11}$ Conforme explicam Lakoff e Johnson (1999), descobertas de Darwin levaram filósofos a rejeitar posições metafísicas relativas à existência humana e a levar em conta a sua natureza corpórea. Nesse contexto, os autores ressaltam que os trabalhos dos filósofos Maurice Merleau-Ponty e John Dewey foram essenciais para mostrar a relevância da experiência corpórea no que concerne ao modo como vivemos, interagimos e compreendemos o mundo.

${ }^{12}$ No original: "[...] as animals we have bodies connected to the natural world, such that our consciousness and rationality are tied to our bodily orientations and interactions in and with our environment. Our embodiment is essential to who we are, to what meaning is, and to our ability to draw rational inferences and to be creative." (JOHNSON, 1987, p. xxxviii).

${ }^{13}$ No original: "It includes [...] not merely perception, motor movement, etc., but especially the internal genetically acquired makeup of the organism and the nature of its interactions in both its physical and its social environments." (LAKOFF, [1987]1990, p. xv).

${ }^{14}$ No original: "Reason is not disembodied, as the tradition has largely held, but arises from the nature of our brains, bodies, and bodily experience. [...] The same neural and cognitive mechanisms that allow us to perceive and move around also create our conceptual systems and modes of reason. [...] In summary, reason is not, in any way, a transcendent feature of the universe or of disembodied mind. Instead, it is shaped crucially by the peculiarities of our human bodies, by the remarkable details of the neural structure of our brains, and by the specifics of our everyday functioning in the world." (LAKOFF; JOHNSON, 1999, p. 4).

${ }^{15}$ No original: “[...] a central role in the constitution of rationality”. (JOHNSON, 1987, p. ix). 
${ }^{16}$ No original: "[...] consists of interaction with other people and other minds. This leads to mutual recognition [...] as well as to substantial convergence in the mental worlds constructed". (LANGACKER, 1999, p. 233).

${ }^{17}$ No original: "Meaning is not a thing; it involves what is meaningful to us. Nothing is meaningful in itself. Meaningfulness derives from the experience of functioning as a being of a certain sort in an environment of a certain sort." (LAKOFF, [1987]1990, p. 292).

${ }^{18}$ No original: “[...] eliminates cognitive organization from the linguistic system.” (SWEETSER, 1990, p. 4).

${ }^{19}$ No original: "[...] providing a characterization of the general principles for language that accord with what is known about the mind and brain from other disciplines." (EVANS; BERGEN; ZINKEN, 2006, p. 4).

${ }^{20}$ No original: "Language does not 'represent' meaning; it prompts for the construction of meaning in particular contexts with particular cultural models and cognitive resources." (FAUCONNIER, 2003, p. 2).

${ }^{21}$ No original: "[...] a lexical meaning resides in a particular way of accessing an open-ended body of knowledge pertaining to a certain type of entity." (LANGACKER, 2008, p. 40, grifo do autor).

${ }^{22}$ Exemplos de palavras-dicionário seriam fenômenos como luz e calor, enquanto palavras-objeto diriam respeito a pesquisas científicas e a outros conhecimentos gerais (HAIMAN, 1980).

${ }^{23}$ No original: "Without experience, there is no thought, and certainly no language." (HAIMAN, 1980, p. 337)

${ }^{24}$ No original: "[...] you can define birds as a certain type of animal with certain characteristics (like having wings, being able to fly, and being born from eggs), but if you want to get a good cognitive grip on what birds are, you will want to have a look at some typical birds like robins and sparrows and doves, and then maybe also at some less typical ones, like chickens and ostriches." (GEERAERTS, 2006, p. 1).

${ }^{25}$ No original: "[...] cognitive operations which realize the production and comprehension of linguistic utterances. Because the relationship between words and the world is mediated by cognitive activity, the study of meaning is the study of meaning is the study of how words are used to evoke mental representations." (COULSON, 1997, p. 17).

${ }^{26}$ No original: “[...] the locus of meaning”. (LANGACKER, 1999, p. 229)

${ }^{27}$ No original: "[...] novel conceptions as well as fixed concepts; sensory, kinesthetic, and emotive experience; recognition of the immediate context (social, physical, and linguistic); and so on." (LANGACKER, 2006, p. 30)

${ }^{28}$ No original: "In speaking, we conceptualize not only what we are talking about but also the context in all its dimensions, including our assessment of the knowledge and intentions of our interlocutor." (LANGACKER, 2013, p. 29).

${ }^{29}$ No original: "[...] empty heads cannot talk, interact, or negotiate meanings". (LANGACKER, 2013, p. 29).

${ }^{30}$ No original: "Linguistic meanings are also grounded in social interaction, being negotiated by interlocutors based on mutual assessment of their knowledge, thoughts, and intentions." (LANGACKER, 2008, p. 4).

${ }^{31}$ Movimento fictício concerne à captura de movimentos não verídicos de entidades - por exemplo, Essa praça vai até o final da quadra. Opõe-se a movimento factivo, que se refere a movimentos verídicos, como Fui à praça pela manhã. (CASTILHO, 2011). 
${ }^{32}$ No original: "[...] people simulate motion [...] while trying to understand FM [fictive motion] sentences." (MATLOCK, 2004, p. 1396)

${ }^{33}$ Informação verbal coletada durante a comunicação do professor Augusto Soares da Silva na mesa redonda Polissemia, Cognição e discurso, que ocorreu no I Congresso Ibero-Americano de Semântica Cognitiva (CISCOG), realizado em Salvador, no dia 27 de outubro de 2015.

${ }^{34}$ Do inglês sociocultural situatedness (SILVA, 2009, p. 518).

\section{REFERÊNCIAS}

BORGES NETO, J. Semântica Formal. Revista Letras, Curitiba, n. 52, p. 167-182, jul./dez. 1999. Disponível em: <http://ojs.c3sl.ufpr.br/ojs/index.php/letras/article/download/18948/12268>. Acesso em: setembro 2015.

CARROL, L. Alice: aventuras de Alice no País das Maravilhas \& através do espelho e o que Alice encontrou por lá. Rio de Janeiro: Zahar, 2010.

COULSON, S. Semantic leaps. The role of frame-shifting and conceptual blending in meaning construction. 326 p. Dissertation (Doctor of Philosophy in Cognitive Science) - Department of Cognitive Science, University of California (UCLA), San Diego, 1997. Disponível em: $<$ http://www-cogsci.ucsd.edu/research/documents/dissertations/coulson_thesis.pdf $>$. Acesso em: julho 2015.

COULSON, S. Semantic leaps. Frame-shifting and conceptual blending in meaning construction. New York: Cambridge University Press, 2001.

EVANS, V.; BERGEN, B.K.; ZINKEN, J. The cognitive linguistics reader. London/Oakville: Equinox Publishing, 2007.

FAUCONNIER, G. Cognitive Linguistics. In: NADEL, L. Encyclopedia of cognitive science. London: Macmillan, 2003.

GEERAERTS, D. Introduction: A rough guide to Cognitive Linguistics. In: GEERAERTS, D. (Ed.). Cognitive linguistics: basic readings. Berlin: Mouton de Gruyter, 2006.

HAIMAN, J. Dictionaries and encyclopedias. Lingua, Amsterdam, North-Holland Publishing Company, n. 50, p. 329-357, 1980. Disponível em: <http://www.sciencedirect.com/science/ article/pii/0024384180900893>. Acesso em: 23 nov.

JOHNSON, M. The body in the mind. The bodily basis of meaning, imagination, and reason. Chicago: The University of Chicago Press, 1987.

JOHNSON, M. The philosophical significance of image schemas. In: HAMPE, B. (Ed.). From perception to meaning: image schemas in Cognitive Linguistics. Berlin, New York: Mouton de Gruyter, 2005.

KAUFFMANN 2006. Conditionals. In: BARBER, A.; STAINTON, R.J. Encyclopedia of philosophy of language and Linguistics. Oxford: Elsevier, 2010. 
KÖVECSES, Z. Language, mind and culture: a practical introduction. New York: Oxford University Press, 2006.

KÖVECSES, Z. Meaning-making: the bigger picture. An interview with Zoltán Kövecses. [2009]. Entrevistadora: Réka Benczes. Annual Review of Cognitive Linguistics, n. 7, Amsterdam, John Benjamins, 2009.

LAKOFF, G. Women, fire and dangerous things: what categories reveal about mind. Chicago: The University of Chicago Press, 1980.

LAKOFF, G. George Lakoff on embodied cognition and language. [S.1.], 2013. (1 h $28 \mathrm{~min}$ ). Disponível em: <https://www.youtube.com/watch?v=XWYaoAoijdQ $>$. Acesso em: junho 2014.

LAKOFF, G.; JOHNSON, M. Philosophy in the flesh: the embodied mind and its challenge to western thought. New York: Basic Books, 1999.

LAKOFF, G.; JOHNSON, M. Metaphors we live by. London: The University of Chicago Press, 2003.

LANGACKER, R.W. Foundations of cognitive grammar: theoretical prerequisites. Stanford: Stanford University Press, 1987.

LANGACKER, R.W. The contextual basis of cognitive semantics. In: NUYTS, J.; PEDERSON, E. Language and conceptualization. Cambridge: Cambridge University Press, 1997.

LANGACKER, R.W. Cognitive Grammar: a basic introduction. New York: Oxford University Press, 2008.

LANGACKER, R.W. Essentials of Cognitive Grammar. New York: Oxford University Press, 2013.

LYONS, J. Semántica Lingüística: una introducción. Barcelona: Paidós, 1997.

MARTIN, R.M. Meaning: overview of philosophical theories. In: BROWN, K. (Ed.) Encyclopedia of Language and Linguistics. Oxford: Elsevier, 2006.

MATLOCK, T. Fictive motion as cognitive simulation. Memory \& Cognition, v. 32, n. 8, p. 1389-1400, 2004. Disponível em: <http://faculty.ucmerced.edu/tmatlock/papers/Matlock,\%20Te enie- $\% 2023 . \% 20$ Fictive $\% 20$ Motion $\% 20$ as\%20Cognitive $\% 20$ Simulation $\% 20$.pdf $>$. Acesso em: 25 out. 2015.

MIRANDA, N.S. O caráter partilhado da construção da significação. Veredas: Revista de Estudos Linguísticos, Juiz de Fora, v. 5, n. 1, p. 57-81, 2001. Disponível em: <http://www.ufjf.br/revista veredas/files/2009/12/artigo49.pdf $>$. Acesso em: dezembro 2015.

NUYTS, J.; PEDERSON, E. Language and conceptualization. Cambridge: Cambridge University Press, 1997.

ROSCH, E. Natural categories. Cognitive Psychology, v. 4, n. 3, p. 328-350, 1973. 
SALOMÃO, M.M. Gramática e interação: o enquadre programático da hipótese sociocognitiva sobre a linguagem. Veredas: revista de estudos linguísticos, Juiz de Fora, v. 1, n. 1, 1997, p. 23-39. Disponível em: <http://www.ufjf.br/revistaveredas/files/2009/12/nova-digitaliza\%C3\%A7\%C3\% A3o-artigo-Salom\%C3\%A3o.pdf $>$. Acesso em: novembro 2015.

SALOMÃO, M.M. Teorias da linguagem: a perspectiva sociocognitiva. In: FÓRUM DE LINGUAGEM, 2, 2006, Rio de Janeiro. Anais... Rio de Janeiro: Universidade Federal do Rio de Janeiro, 2006. p. 1-13.

SILVA, A.S. O cognitivo e o social nos estudos linguísticos: inimigos íntimos? In: ENCONTRO NACIONAL DA ASSOCIAÇÃO PORTUGUESA DE LINGUÍSTICA, 24, 2009, Lisboa. Disponível em: < http://www.apl.org.pt/docs/24-textos-seleccionados/35-Silva.pdf>. Acesso em: junho 2015.

SWEETSER, E. From etymology to pragmatics. Metaphorical and cultural aspects of semantic structure. New York: Cambridge University Press, 1990.

TALMY, G. Beyond foreground and background. In: TOMLIN, R.S. (Ed.). Coherence and grounding in discourse. Amsterdam/Philadelphia: John Benjamins, 1987.

TAYLOR, J.R. Cognitive Grammar. New York: Oxford University Press, 2002.

TAYLOR, J.R. Cognitive Semantics. In: BROWN, K. (Ed.). Encyclopedia of Language and Linguistics. Oxford: Elsevier, 2005.

TAYLOR, J.R. Linguistic categorization. New York: Oxford University Press, 2009.

TOMASELLO, M. The key is social cognition. In: GENTNER, D.; GOLDIN-MEADOW, S. Language in mind. Advances in the study of language and thought. Cambridge: The MIT Press, 2003.

TOMASELLO, M. The cultural origins of human cognition. Cambridge: Harvard University Press, 1999.

TURNER, M. Cognitive Dimensions of Social Science. New York: Oxford University Press, 2001. 